\title{
Coagulation of methylated arsenic from drinking water: Influence of methyl substitution
}

\author{
Chengzhi Hu*, Qingxin Chen, Huijuan Liu, Jiuhui Qu
}

Key Laboratory of Drinking Water Science and Technology, Research Center for Eco-Environmental Sciences, Chinese Academy of Sciences, Beijing 100085 , China

\section{H I G H L I G H T S}

- $\mathrm{FeCl}_{3}$ was more efficient than $\mathrm{Al}$ salts in methylated As removal by coagulation.

- As removal was negatively correlated with the degree of methyl substitution.

- Adsorption on Fe/Al hydroxide flocs was major coagulation mechanism of methylated As.

- As-O group of methylated As substituted $\mathrm{O}-\mathrm{H}$ group of $\mathrm{Fe} / \mathrm{Al}$ hydroxide to form complex.

\section{G R A P H I C A L A B S T R A C T}

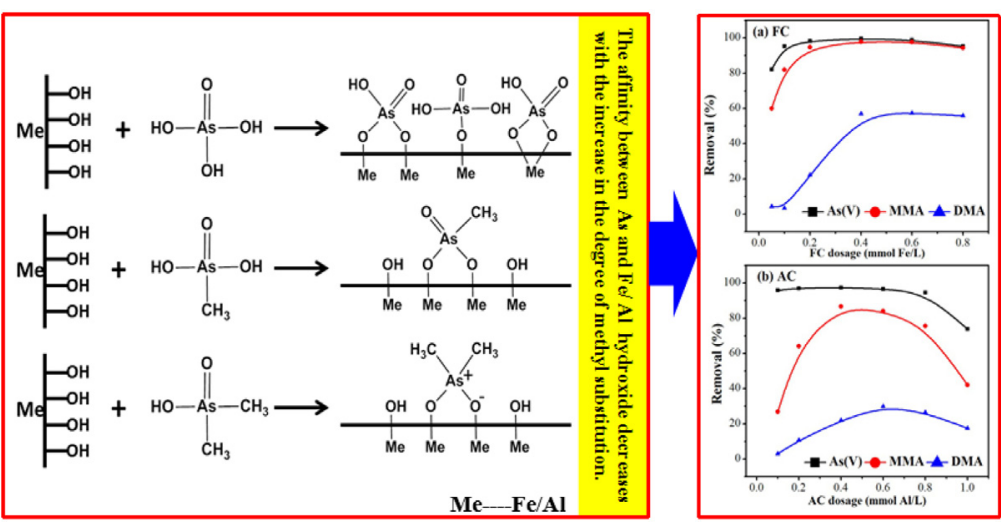

\begin{abstract}
A B S T R A C T
Methylated arsenic can be found in virtually all earth surface environments. So far, however, little information has been collected regarding their removal by coagulation. In this study, the removal of monomethylarsenate (MMA) and dimethylarsenate (DMA) from drinking water by coagulation was investigated from the viewpoint of methyl substitution. Results indicated that $\mathrm{FeCl}_{3}$ was more efficient than $\mathrm{AlCl}_{3}$ and polyaluminum chloride (PACl) in methylated As removal. For the initial arsenic concentration of $200 \mu \mathrm{g} / \mathrm{L}$, an $\mathrm{FeCl}_{3}$ dosage of $0.2 \mathrm{mmol} \mathrm{Fe} / \mathrm{L}$ was sufficient to attain about $95 \%$ removal of MMA, while a dosage of $0.6 \mathrm{mmol} \mathrm{Fe} / \mathrm{L}$ achieved about $57 \%$ removal of DMA. Arsenic removal efficiency was negatively correlated with the degree of methyl substitution. With the increase in methyl group number, the quantity of negatively charged arsenic species decreased and molecular size increased, leading to the decrease of methylated As removal by coagulation. Adsorption on preformed hydroxide flocs was the major mechanism during coagulation. Both FTIR and XPS results indicated that the As-O group of As might substitute the $\mathrm{O}-\mathrm{H}$ group of $\mathrm{Fe} / \mathrm{Al}$ hydroxide to form a $\mathrm{Fe} / \mathrm{Al}-\mathrm{O}-\mathrm{As}$ complex. Furthermore, the use of traditional oxidants and coagulation aids exhibited limited help for improving coagulation removal of DMA.

(c) 2015 Elsevier B.V. All rights reserved.
\end{abstract}

\footnotetext{
* Corresponding author. Tel.: +86 10 6284960; fax: +861062849160.

E-mail address: czhu@rcees.ac.cn (C. Hu).
}

\section{Introduction}

Arsenic (As) is of considerable environmental concern due to its toxicity [1], with drinking water, the main source of As exposure for 

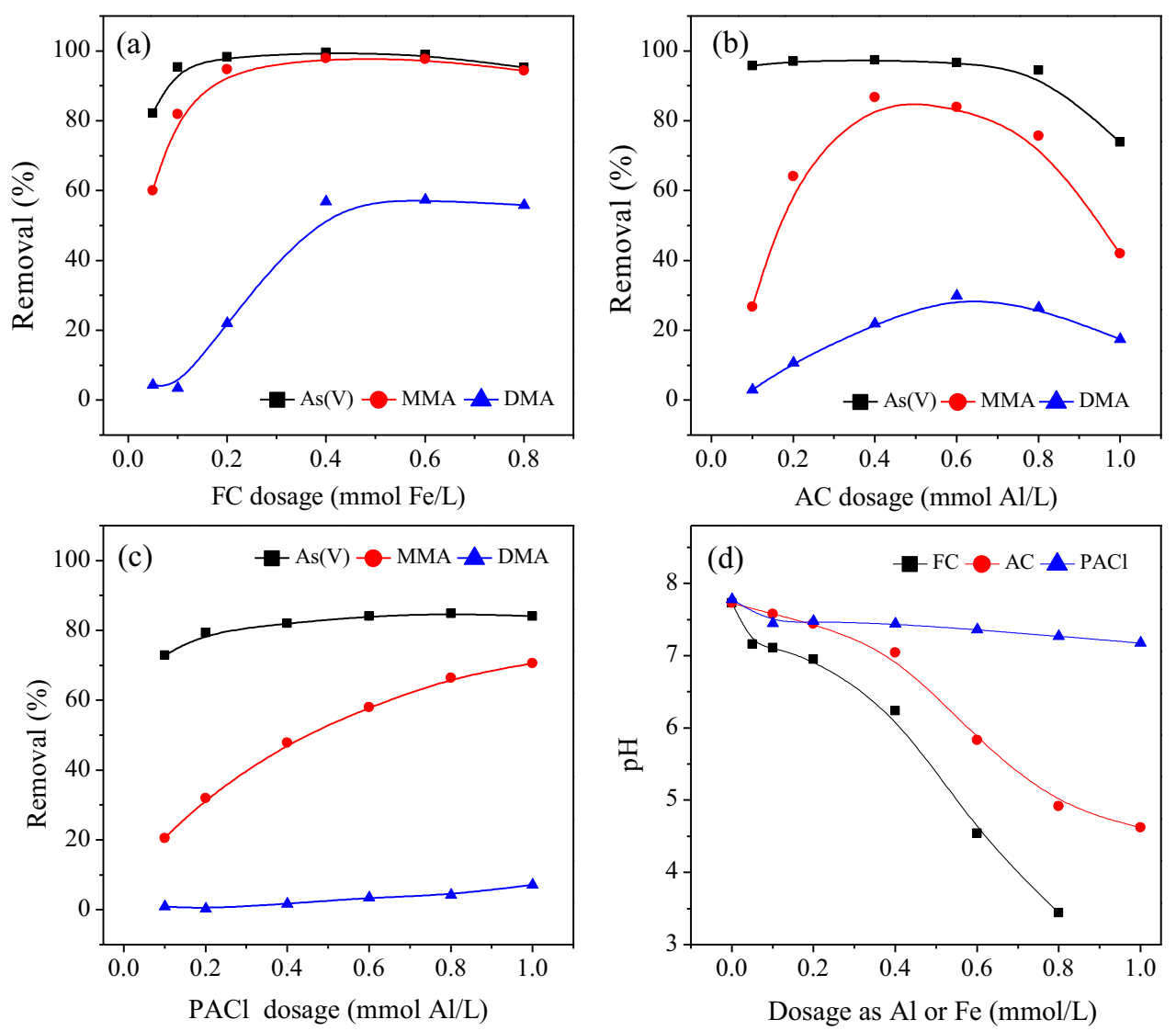

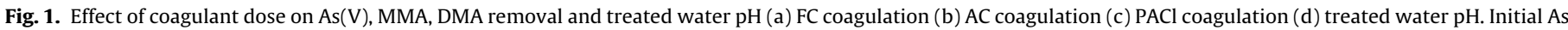
concentration was $200 \mu \mathrm{g} \mathrm{As} / \mathrm{L}$.

humans [2]. Although inorganic $\mathrm{As}(\mathrm{V})$ and $\mathrm{As}(\mathrm{III})$ are the most common arsenic species in the environment, organic forms of As can also be found in nature, typically occurring as monomethylarsenate (MMA) and dimethylarsenate (DMA) [3]. Previous research reported that $19.4 \%$ and $5.0 \%$ of total As occurred as DMA and MMA, respectively, in a Californian lake [4], and $24.1 \%$ of total As occurred as DMA (3.5 $\mu \mathrm{g}$ As/L) in a southwest Spanish river [5], where methylated As may threaten the safety of drinking water. In addition, MMA and DMA concentrations were found to be 35.4-233.9 $\mu \mathrm{g}$ As/L and 3.5-13.1 $\mu \mathrm{g}$ As/L from a source of drinking water in Inner Mongolian, respectively [6]. Some bacteria and fungi can produce MMA and DMA through the methylation of inorganic As [7]. Furthermore, MMA and DMA can be introduced into the environment through agricultural activities [8] with both used as herbicides and pesticides over the past several decades [7,9]. Although inorganic As has long been considered more toxic than organic As [10], some methylated As, such as MMA(III), is reportedly much more toxic than inorganic As [11]. Thus, the reduction of MMA and DMA can produce very toxic MMA(III) and DMA(III), respectively.

As a result of the widespread distribution and toxicity of methylated As in the environment, research on methylated As removal from water has grown in importance. The adsorption of MMA and DMA on several minerals has been studied previously [9,12-16]. Results found that adsorption of DMA on goethite and ferrihydrite was reportedly low compared with As(V) and MMA [13], adsorption of $\mathrm{As}(\mathrm{V})$ on aluminum oxide reached $100 \%$ within $5 \mathrm{~min}$, while $78 \%$ and $15 \%$ of MMA and DMA were adsorbed, respectively [15], and adsorption of MMA on nanocrystalline $\mathrm{TiO}_{2}$ achieved $100 \%$ at pH 7.5, with DMA removal reaching 65\% at pH 5.5 [17].

The number of methyl groups of As(V), MMA and DMA is 0,1 and 2 , respectively. Variation in methyl substitution degree can lead to remarkable differences in the adsorption behavior of As onto $\mathrm{Fe} / \mathrm{Al}$ oxides. Coagulation by $\mathrm{Fe}$ - and Al-based salts have been used as the most practical choice for As removal from drinking water [18,19]. Many studies have investigated the coagulation removal of inorganic As [20-23]. However, only limited information is available on the removal of organic As by coagulation [24], and the removal of methylated As from drinking water by coagulation has not yet been studied. Furthermore, the influence of methyl substitution on As coagulation by $\mathrm{Fe} / \mathrm{Al}$-based salts is still unclear.

We investigated the coagulation efficiency and behavior of methylated As in drinking water from the viewpoint of methyl substitution. The removal of As(V), MMA and DMA was examined under various conditions including coagulant type, coagulant dose, and water $\mathrm{pH}$. The mechanisms of methylated As removal by $\mathrm{Al} / \mathrm{Fe}$-based coagulants were also studied through particular coagulation/adsorption experiments. The interaction of flocs with $\mathrm{As}(\mathrm{V})$, MMA and DMA was characterized using Fourier transform infrared spectrometry (FTIR) and X-ray photoelectron spectrometry (XPS). We also evaluated the addition of common oxidants and coagulant aids to enhance methylated As removal by coagulation.

\section{Material and methods}

\subsection{Materials and analysis methods}

All chemical solutions used in this study were prepared using de-ionized water and analytical (or better) grade chemicals. $\mathrm{FeCl}_{3}$ (FC), $\mathrm{AlCl}_{3}(\mathrm{AC})$ and polyaluminum chloride (PACl) were used as coagulants. $\mathrm{PACl}$ was prepared by an electrochemical process [25]. The predominant $\mathrm{Al}$ species of $\mathrm{PACl}$ was $\mathrm{Al}_{13}$ polymer, which accounted for $86.3 \%$ of total $\mathrm{Al}$ 


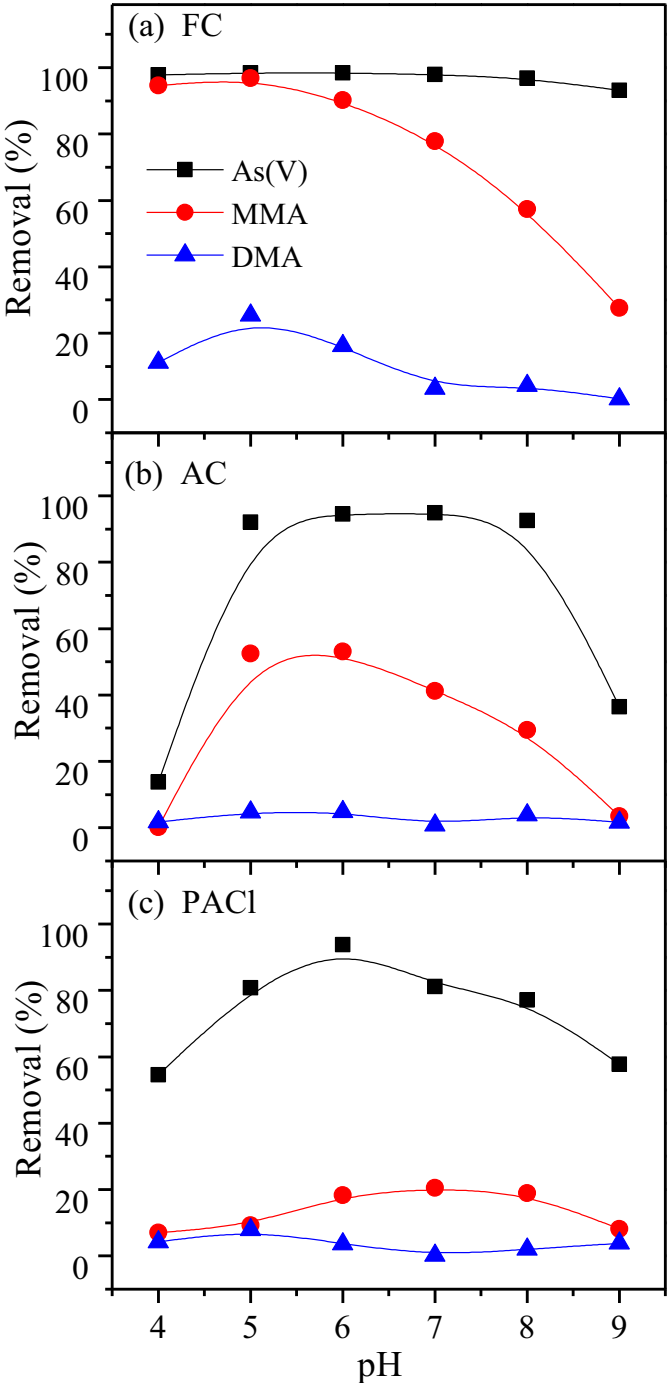

Fig. 2. Effect of $p H$ on $A s(V), M M A$ and $D M A$ removal (a) $F C$ coagulation (b) $A C$ coagulation (c) PACl coagulation. Initial As concentration was $200 \mu \mathrm{g}$ As/L. Coagulant dosages were $0.1 \mathrm{mmol} / \mathrm{L}$.

concentration as analyzed by the Ferron colorimetric method [26]. $\mathrm{Na}_{2} \mathrm{HAsO}_{4} \cdot 7 \mathrm{H}_{2} \mathrm{O}$ (Sigma, USA), $\mathrm{CH}_{4} \mathrm{AsNaO}_{3} \cdot 1.5 \mathrm{H}_{2} \mathrm{O}$ (Sigma, USA) and $\mathrm{C}_{2} \mathrm{H}_{6} \mathrm{AsNaO}_{2} \cdot 3 \mathrm{H}_{2} \mathrm{O}$ (J\&K, China) were used to prepare $400 \mathrm{mg} / \mathrm{L} \mathrm{As}(\mathrm{V}), \mathrm{MMA}$ and DMA stock solutions, respectively. The initial concentration of As in the experiments was approximately $200 \mu \mathrm{g} / \mathrm{L}$.

Arsenic analysis was conducted using inductively coupled plasma mass spectrometry (Thermo Scientific, USA). The collision cell was switched on to eliminate $\mathrm{Cl}^{-}$interference from ${ }^{40} \mathrm{Ar}^{35} \mathrm{Cl}^{+}$. Each sample was measured three times and the value of RSD could not excess $5 \%$.

\subsection{Jar tests}

Jar tests were performed on a six-paddle stirrer. Sample water $(400 \mathrm{~mL})$ was transferred to a $500 \mathrm{~mL}$ beaker. The process included $2 \mathrm{~min}$ of rapid stirring $(200 \mathrm{rpm}), 15 \mathrm{~min}$ of slow stirring $(40 \mathrm{rpm})$ and $30 \mathrm{~min}$ of settling, after which the supernatants were filtered by $0.45 \mu \mathrm{m}$ pore size membranes and measured by ICP-MS for As. Water pH was accurately adjusted to the expected values by adding $\mathrm{HCl}$ or $\mathrm{NaOH}$ solution after dosing with coagulants during the rapid stirring period, after which water $\mathrm{pH}$ was almost constant in the following processes.

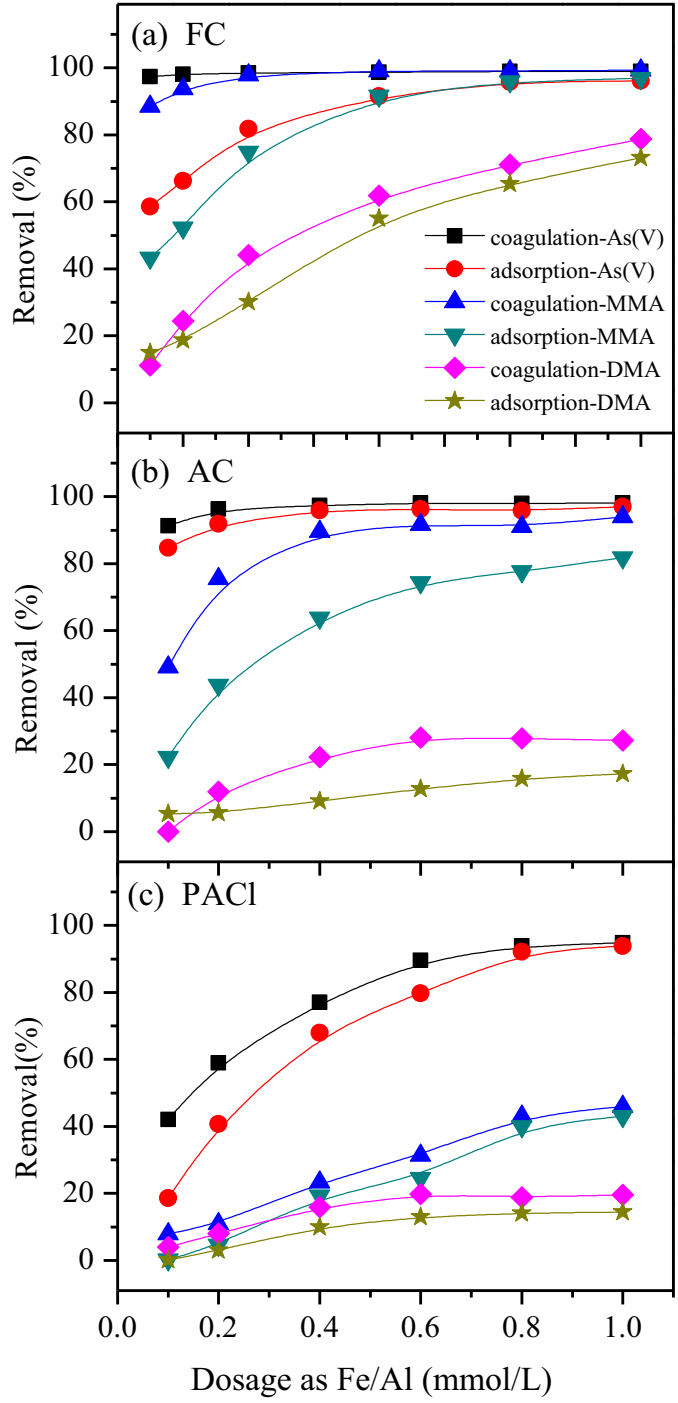

Fig. 3. As(V), MMA and DMA removal by coagulation and adsorption on preformed hydroxide flocs (a) FC coagulation (b) AC coagulation (c) PACl coagulation. Initial As concentration was $200 \mu \mathrm{g}$ As/L. pH value was 5.

Some common oxidants and coagulant aids were used to enhance DMA removal by coagulation. A certain amount of $\mathrm{KMnO}_{4}$, $\mathrm{NaClO}$ and powdered activated carbon (PAC) were added into the sample water at the beginning of the coagulation process, and FC was then added after 20 min. A certain amount of chitosan (deacetylation degree 80-95\%) was added into the sample water after FC addition in the rapid stirring period. The treated water was taken for As measurement.

\subsection{Adsorption experiments}

Adsorption experiments were initiated to evaluate $\mathrm{As}(\mathrm{V}), \mathrm{MMA}$ and DMA removal by adsorption on preformed $\mathrm{Al} / \mathrm{Fe}$ hydroxide flocs. In the water samples without As, hydroxide flocs formed during the slow stirring period. A certain amount of As was then added into the preformed flocs suspension and another $15 \mathrm{~min}$ of slow stirring was performed to allow for As adsorption. The settling step was applied after the adsorption step. The experimental conditions for adsorption were the same for coagulation. The removal performance of As by adsorption was then compared with that by coagulation. 

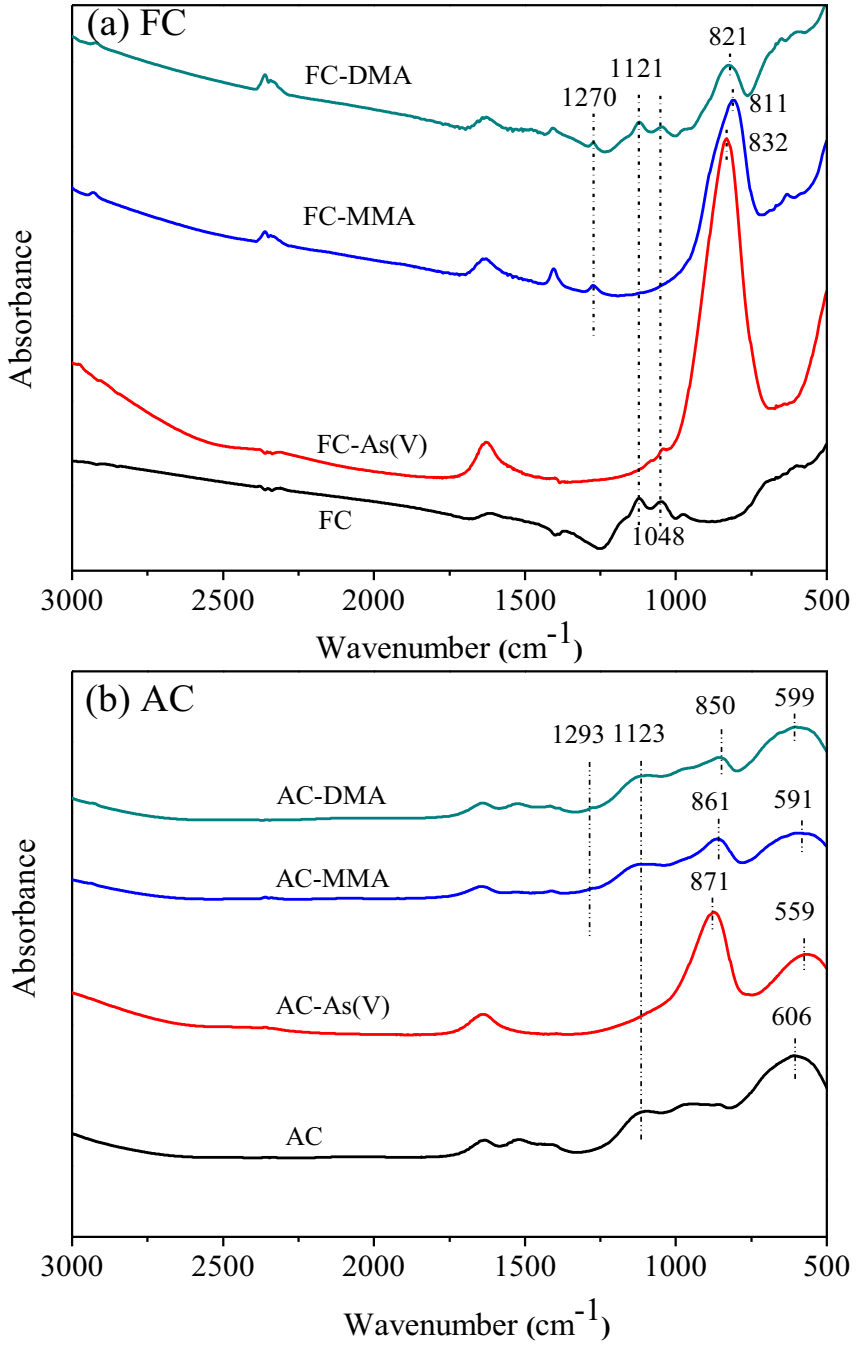

Fig. 4. FTIR spectra for flocs obtained from coagulation by FC/AC. (a) FC coagulation (b) $\mathrm{AC}$ coagulation. $\mathrm{As} / \mathrm{Fe}=\mathrm{As} / \mathrm{Al}=1.2(\mathrm{w} / \mathrm{w})$.

\subsection{Flocs characterization by FTIR and XPS}

When coagulation finished, the flocs were accumulated by settling and centrifuging, and then freeze-dried for FTIR and XPS characterization. FTIR spectra were collected on a Nicolet 5700 spectrometer using absorbance mode. Samples for FTIR were ground with spectral grade $\mathrm{KBr}$ in an agate mortar. A fixed sample ratio $(2 \% \mathrm{w}: \mathrm{w})$ was used to prepare the pellet. XPS data were collected on an ESCA-Lab-220i-XL spectrometer with monochromatic $\mathrm{Al} \mathrm{K} \alpha$ radiation $(1486.6 \mathrm{eV}) . \mathrm{C} 1 \mathrm{~s}$ peaks were used as an inner standard calibration peak at $284.7 \mathrm{eV}$.

\section{Results and discussion}

\subsection{Effect of coagulant dose on arsenic removal}

Fig. 1 shows the results of $\mathrm{As}(\mathrm{V})$, MMA and DMA removal by $\mathrm{FC}, \mathrm{AC}$ and PACl. With the increase in coagulant dosage, the concentration of As gradually decreased, except at high dosages of AC. Results showed that FC was more effective than Al-based coagulants for methylated As removal. The removal efficiency of MMA by FC reached above $95 \%$ at dosages of more than $0.2 \mathrm{mmol} \mathrm{Fe} / \mathrm{L}$, while the maximum removal efficiency by Al-based coagulants was about $84.1 \%$ at the $\mathrm{AC}$ dosage of $0.4 \mathrm{mmol} \mathrm{Al} / \mathrm{L}$. The removal of DMA by FC was also notably higher than that by the two Al salts at the same dosage. Fig. 1 shows the removal efficiency of As was $\mathrm{As}(\mathrm{V})>\mathrm{MMA}>\mathrm{DMA}$. The removal efficiency of methylated As decreased with the increase in the degree of methyl substitution. After the addition of $0.2 \mathrm{mmol} / \mathrm{L} \mathrm{FC}$, the removal efficiencies of $\operatorname{As}(\mathrm{V})$, MMA and DMA were $98.3 \%, 94.7 \%$ and $22.1 \%$, respectively. MMA removal exhibited a similar trend as As $(\mathrm{V})$ during the FC coagulation process. MMA concentrations in the treated water met the required maximum contaminant level $(10 \mu \mathrm{g}$ As/L) when adding more than $0.2 \mathrm{mmol} / \mathrm{L}$ FC. Fig. 1 also indicates that AC exhibited better coagulation performance than that of PACl. DMA removal by $\mathrm{PACl}$ coagulation was almost negligible. Accordingly, with respect to DMA, coagulation by Fe and Al-based coagulants was not an effective removal method.

The $\mathrm{pH}$ of treated water was depressed by coagulant addition (Fig. 1(d)). The most significant decline in water $\mathrm{pH}$ was observed by FC coagulation. For Al-based coagulants, the extent of $\mathrm{pH}$ decrease was inverse to coagulant basicity $\left(\left[\mathrm{OH}^{-}\right] /\left[\mathrm{Al}_{\mathrm{T}}\right]\right)$. With the addition of $1.0 \mathrm{mmol} / \mathrm{L} \mathrm{Al}$ salts, the $\mathrm{pH}$ with $\mathrm{AC}$ addition decreased from 7.6 to 4.8 , which was larger than the $\mathrm{pH}$ range observed with $\mathrm{PACl}$. With the addition of more than $0.6 \mathrm{mmol} / \mathrm{L} \mathrm{AC}$, water $\mathrm{pH}$ was less than 6 , under which most hydrous $\mathrm{Al}$ oxides are soluble and less solid $\mathrm{Al}$ hydroxides are formed [27]. Accordingly, As removal decreased at dosages of more than $0.6 \mathrm{mmol} \mathrm{Al} / \mathrm{L}$. The effect of $\mathrm{pH}$ on methylated As removal by coagulation was further investigated, as discussed below.

\subsection{Effect of $\mathrm{pH}$ on arsenic removal}

Fig. 2 shows the effect of $\mathrm{pH}$ on $\mathrm{As}(\mathrm{V}), \mathrm{MMA}$ and DMA removal when $0.1 \mathrm{mmol} / \mathrm{L}$ of coagulants were used. Dosages of $0.6 \mathrm{mmol} / \mathrm{L}$ were also used and exhibited more pronounced removal performance than that of $0.1 \mathrm{mmol} / \mathrm{L}$ dose, although the trend was similar as that observed for As removal (Fig. S1). In the range of $\mathrm{pH} 4-9$, methylated As removal efficiencies with FC were clearly higher than those using the two Al-based coagulants. The optimal pH levels for MMA and DMA removal by FC, AC and PACl were 4-6, 5-7 and $5-8$, respectively. Generally, in weakly acidic $\mathrm{pH}$ conditions, Fe and Al hydroxide flocs readily and largely form due to the minimum solubility of $\mathrm{Fe}$ and $\mathrm{Al}$ in water in this $\mathrm{pH}$ region [27]. Hydroxide flocs may favor methylated As removal through coprecipitation into growing hydroxides and adsorption on preformed hydroxide flocs. The solubility product constant of aluminum hydroxide and that of ferric hydroxide was reported to be about $10^{-33}$ and $10^{-38}$, respectively [27]. Accordingly, hydrous Fe oxide was found to be more insoluble than hydrous Al oxide [18], which produced more flocs during coagulation and which could be helpful for methylated As removal. In addition, the structure of Fe hydroxide appears to be more open and loose than that of Al hydroxide [28], thereby supplying a large available surface area for complexing or adsorbing MMA and DMA. Such factors might contribute to the better performance of FC in As removal. Fig. 2(b) and (c) show that MMA removal by $\mathrm{AC}$ was higher than those by $\mathrm{PACl}$ in the $\mathrm{pH}$ range 5-8. Previous research indicated that, in this $\mathrm{pH}$ region, $\mathrm{Al}_{13}$ species was largely in situ formed during AC coagulation process, which supported the higher removal of As [29]. Fig. 2 also shows DMA removal by AC and $\mathrm{PACl}$ coagulation was almost negligible. $\mathrm{PACl}$ performance in regards to As removal was less dependent on $\mathrm{pH}$ than was AC. This might be the result of the stable characteristics of preformed $\mathrm{Al}$ hydroxide polymers during the $\mathrm{PACl}$ coagulation process.

\subsection{Mechanism of methylated As removal by coagulation}

MMA and DMA are anionic species in water, as shown in Fig. S2. The possible coagulation mechanism, by which anionic contaminants are converted into insoluble products, includes precipitation, coprecipitation, and adsorption [28,30]. Precipitation refers to the 

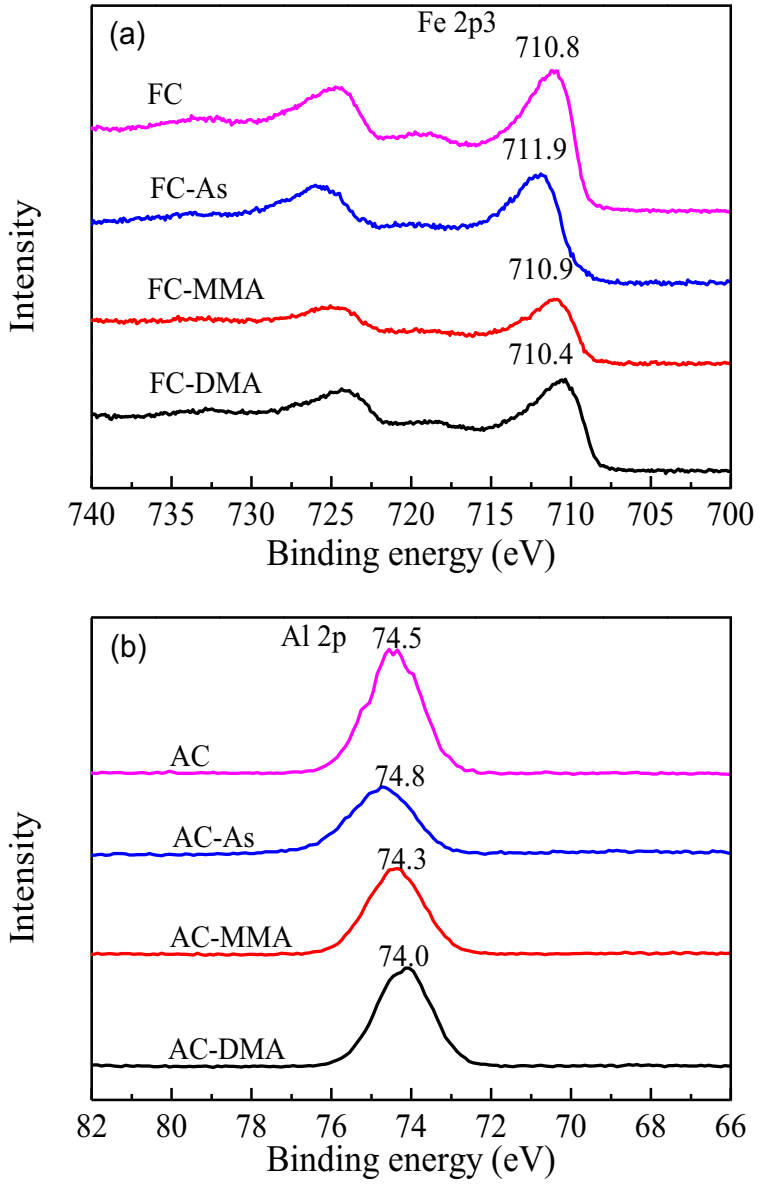

Fig. 5. XPS for flocs obtained from coagulation by FC/AC (a) FC coagulation (b) AC coagulation. $\mathrm{As} / \mathrm{Fe}=\mathrm{As} / \mathrm{Al}=1.2(\mathrm{w} / \mathrm{w})$

insolubilization of contaminants by exceeding a solubility product. Coprecipitation is defined as the incorporation of contaminants into a growing hydroxide phase via inclusion or occlusion. Adsorption refers to the formation of a surface complex between anionic contaminants and a solid hydroxide surface [30]. To explore which mechanism was predominant for methylated As removal in coagulation, the degree of As removal via coagulation was compared with the adsorption removal on preformed hydrous Fe/Al oxide under identical conditions [31,32].

As shown in Fig. 3, the coagulation removal efficiencies of MMA and DMA were much higher than that of adsorption. Adsorption of As occurred as well as precipitation and co-precipitation during coagulation. However, the gap in As removal efficiency between adsorption and coagulation was small. The difference was much more pronounced at low dosages than at high dosages of coagulants for $\mathrm{As}(\mathrm{V})$ and MMA, but the trend for DMA was obscured due to ineffective removal by coagulation. Consequently, results indicated that adsorption on $\mathrm{Fe} / \mathrm{Al}$ hydroxide was the most important mechanism for As removal and precipitation or co-precipitation might also play certain roles, especially at low coagulant dosage. Incorporation of As into the growing hydroxide phase via inclusion or occlusion was difficult due to the fewer hydroxide flocs formed at low coagulant dosage. As removal by both coagulation and adsorption increased with the increase in coagulant dose. Fig. 3 shows that FC exhibited better As removal performance than that of $\mathrm{AC}$ or $\mathrm{PACl}$, which may be attributed to the lower solubility of hydrous Fe oxide and open structure of Fe hydroxide flocs, ensuring a large available surface area for adsorption [28]. The flocs generated from AC coagulation were larger and looser than those generated from
$\mathrm{PACl}$ coagulation [29]. Consequently, AC exhibited much better performance than PACl for MMA and DMA removal.

\subsection{Characterization of coagulation flocs by FTIR and XPS}

Fig. 4(a) shows the FTIR spectra for FC flocs generated from coagulation. The two peaks at 1121 and $1048 \mathrm{~cm}^{-1}$ were assigned to the symmetrical and asymmetrical stretching vibration of the $\mathrm{O}-\mathrm{H}$ group of ferric hydroxide, respectively [33]. After coagulation with As, the two peaks at 1121 and $1048 \mathrm{~cm}^{-1}$ disappeared obviously for $\mathrm{As}(\mathrm{V})$ and MMA, while the intensities of the two peaks became weaker for DMA. These results implied that the $\mathrm{O}-\mathrm{H}$ group of $\mathrm{Fe}$ hydroxide might play an important role in As removal. It could be deduced that the As- $\mathrm{O}$ group of As might substitute the $\mathrm{O}-\mathrm{H}$ group of Fe hydroxide, i.e., the interaction between As and surface hydroxyl of Fe hydroxide was responsible for the attachment of As onto Fe hydroxide. This might be the mechanism for methylated As removal by coagulation and has also been proposed by other researchers when using Fe oxide adsorbents to adsorb $\mathrm{As}(\mathrm{V})$ and As(III) [34-36]. The obscure change in the O-H group of Fe hydroxide for DMA might be ascribed to lower consumption of the $\mathrm{O}-\mathrm{H}$ group during the coagulation process.

Simultaneously, the new peaks that appeared at 831, 811 and $821 \mathrm{~cm}^{-1}$ were assigned to As-O stretching vibration of $\mathrm{As}(\mathrm{V})$, MMA and DMA, respectively [33]. The differences in the As-O vibration position might be attributed to the structural variations of As(V), MMA and DMA. Methyl groups, attached with As, could donate electrons, which would influence the chemical environment around the As-O group. In addition, the peak intensity at $821 \mathrm{~cm}^{-1}$ for DMA was much weaker than the peak intensities of $831 \mathrm{~cm}^{-1}$ for $\mathrm{As}(\mathrm{V})$ and $811 \mathrm{~cm}^{-1}$ for MMA. This might also be attributed to the lower removal of DMA by FC coagulation and less DMA attached to Fe hydroxide. The peak at $1270 \mathrm{~cm}^{-1}$ was assigned to the As- $-\mathrm{CH}_{3}$ group [37], which only exist in the spectrums of MMA and DMA. This phenomenon was consistent with the molecular structure of methylated As.

Fig. 4(b) shows the FTIR spectra for the flocs of AC coagulation. The weak band at $1293 \mathrm{~cm}^{-1}$ was assigned to the As- $-\mathrm{CH}_{3}$ group [37]. The band at $1123 \mathrm{~cm}^{-1}$ was assigned to the stretching vibration of the $\mathrm{O}-\mathrm{H}$ group of Al hydroxide [38,39]. After coagulation with $\mathrm{As}(\mathrm{V})$, MMA and DMA, the peak at $1123 \mathrm{~cm}^{-1}$ obviously disappeared for $\mathrm{As}(\mathrm{V})$ and weakened for MMA, while little change was observed for DMA. The lower removal of MMA and DMA compared with that of $\mathrm{As}(\mathrm{V})$ by $\mathrm{AC}$ coagulation might explain the obscure changes at $1123 \mathrm{~cm}^{-1}$. The three peaks that appeared at 871,861 and $850 \mathrm{~cm}^{-1}$ were assigned to As-O stretching vibration for $\mathrm{As}(\mathrm{V}), \mathrm{MMA}$ and DMA, respectively [33]. The peak at $606 \mathrm{~cm}^{-1}$ was assigned to the stretching vibration of the $\mathrm{Al}-\mathrm{O}$ group of $\mathrm{Al}$ hydroxide $[39,40]$. After coagulation with As(V), MMA and DMA, the position of the $\mathrm{Al}-\mathrm{O}$ group shifted to 559,591 and $599 \mathrm{~cm}^{-1}$, respectively. It was concluded that the As-O group of As might substitute the $\mathrm{O}-\mathrm{H}$ group of $\mathrm{Al}$ hydroxide and a surface complex in the form $\mathrm{Al}-\mathrm{O}-\mathrm{As}$ could be constructed during coagulation. With the increase in methyl group number in methylated As, the electron atmosphere above the $\mathrm{Al}-\mathrm{O}$ bond in the surface complex would move towards the center of $\mathrm{Al}$ and $\mathrm{O}$. This could lead to an increase in the force constant of the $\mathrm{Al}-\mathrm{O}$ bond. As a result, the vibration frequency of $\mathrm{Al}-\mathrm{O}$ would increase, resulting in an increase in $\mathrm{Al}-\mathrm{O}$ wavenumber.

The XPS of Fe 2p and $\mathrm{Al} 2 \mathrm{p}$ of the flocs obtained from FC and AC coagulation are illustrated in Fig. 5. The Fe 2p binding energy of pure Fe hydroxide flocs was $710.8 \mathrm{eV}$. After coagulation with $\mathrm{As}(\mathrm{V})$, MMA and DMA, the Fe 2p binding energies shifted to 711.9, 710.9 and $710.4 \mathrm{eV}$, respectively, which were negatively correlated with the degree of methyl substitution. The binding energy change of Fe 2p might be attributed to surface complexation between As and 

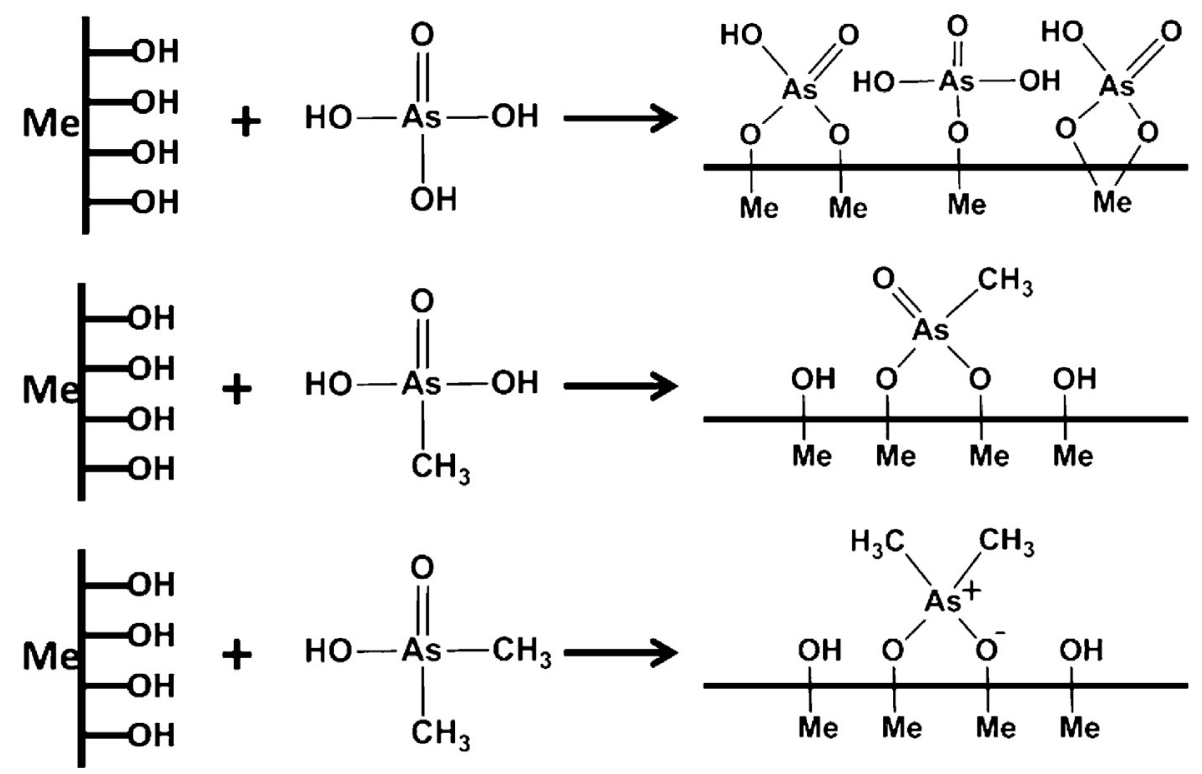

Fig. 6. Interaction mechanism between methylated $\mathrm{As}$ and $\mathrm{Fe} / \mathrm{Al}(\mathrm{Me})$ hydroxide during coagulation.

Fe hydroxide. With the increase in methyl substitution degree, the electron density around the Fe atom increased. This change might have caused the binding energy of Fe $2 p$ to decrease gradually. The $\mathrm{Al} 2 \mathrm{p}$ binding energy of pure $\mathrm{Al}$ hydroxide flocs was $74.5 \mathrm{eV}$. After coagulation with $\mathrm{As}(\mathrm{V})$, MMA and DMA, the Al 2p binding energies shifted to $74.8,74.3$ and $74.0 \mathrm{eV}$, respectively, showing similar trends to FC coagulation.

During the coagulation process, the As-O group of As(V), MMA and DMA substituted the $\mathrm{O}-\mathrm{H}$ group of Fe/Al hydroxide to form a $\mathrm{M}-\mathrm{O}-\mathrm{As}$ complex. Methyl substitution significantly influenced the interaction between As and Fe/Al hydroxide, leading to the remarkable differences in As removal by coagulation. The influence of methyl substitution on coagulation could be explained by the following points. Firstly, as shown in Fig. S2, the number of de-protonation sites for As(V), MMA and DMA were 3, 2 and 1, respectively. As a result, $\mathrm{As}(\mathrm{V})$ had the largest quantity of negatively charged species, while DMA had the smallest quantity at any $\mathrm{pH}$ environment. Consequently, electrostatic attraction with positively charged metal hydroxide was highest for $\mathrm{As}(\mathrm{V})$ and lowest for DMA. This would influence the coagulation removal efficiency of $\mathrm{As}(\mathrm{V})$,
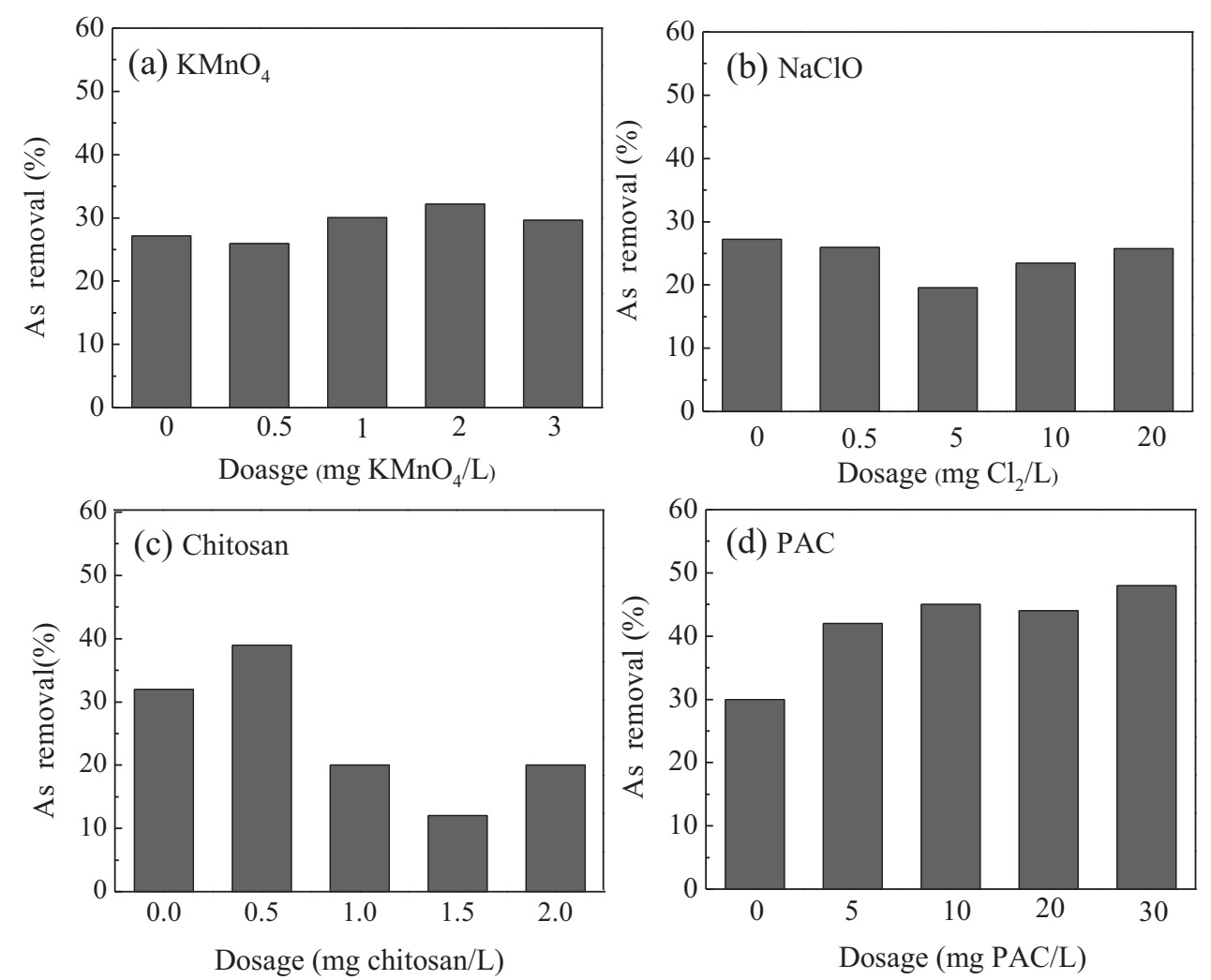

Fig. 7. Performance of some methods to enhance DMA removal (FC dosage was $0.2 \mathrm{mmol} / \mathrm{L}$. Initial pH was 7.80. Initial DMA concentration was $200 \mu \mathrm{g}$ As/L). 
MMA and DMA. Secondly, the variation in molecular structure also influenced the removal efficiency of methylated As by coagulation. Average As- $\mathrm{O}$ distance was found to be about $1.7 \AA \hat{\AA}$, and average As-C distance was about $1.9 \AA$ $[41,42]$. Consequently, the substitution of the $-\mathrm{CH}_{3}$ group for the $-\mathrm{OH}$ group would make the molecular sizes of MMA and DMA larger than As(V), which might hinder surface complexation between As and Fe/Al hydroxide. As a result, the removal efficiency of As was negatively correlated with methyl substitution degree. As(V) can form three different surface complexes on Fe/Al oxide, including monodentate complex, bidentate binuclear complex and bidentate mononuclear complex $[41,43]$, while both MMA and DMA can form bidentate binuclear complexes on $\mathrm{Fe} / \mathrm{Al}$ oxide $[15,42]$. As(V) has more possible edge sites than MMA and DMA when forming complexes with $\mathrm{Fe} / \mathrm{Al}$ oxide due to more hydroxyl groups when compared with methylated As [15]. Fewer reactive sites might result in lower adsorption affinity on $\mathrm{Fe} / \mathrm{Al}$ hydroxide, leading to the decrease in coagulation removal efficiency of As with the increase in methyl substitution degree. In addition, the formation of a bidentate binuclear complex between DMA and $\mathrm{Fe} / \mathrm{Al}$ oxide requires that both $\mathrm{As}=\mathrm{O}$ and the As- $\mathrm{OH}$ group are involved in the complexation, while the formation of the complex between MMA or $\mathrm{As}(\mathrm{V})$ and $\mathrm{Fe} / \mathrm{Al}$ oxide only requires the involvement of two As- $\mathrm{OH}$ groups [15,42]. Thus, the complex structure between DMA and Fe/Al oxide can be less stable than the complex structure for MMA or $\mathrm{As}(\mathrm{V})$ [15]. This can also contribute to the lower adsorption affinity on Fe/Al hydroxide and lower removal by Fe/Al salt coagulation for DMA than that for MMA or $\mathrm{As}(\mathrm{V})$. The possible interaction mechanism between methylated As and $\mathrm{Fe} / \mathrm{Al}$ hydroxide during the coagulation process is illustrated in Fig. 6.

\subsection{Evaluation of common methods to enhance DMA removal}

As a result of the limited removal of DMA by coagulation, supplementary methods such as pre-oxidation and coagulant aids were used to enhance DMA removal. $\mathrm{NaClO}$ and $\mathrm{KMnO}_{4}$, which are common pre-oxidants in drinking water treatment, were used to pre-oxide DMA to $\mathrm{As}(\mathrm{V})$ or MMA and were subsequently removed by coagulation. As shown in Fig. 7(a) and (b), the removal efficiency of As remained almost unchanged after adding various doses of $\mathrm{NaClO}$ or $\mathrm{KMnO}_{4}$. The results indicated that the $-\mathrm{CH}_{3}$ group of DMA was difficult to destroy by the oxidants. The use of ozone also exhibits limited destruction of DMA [44].

Previous research demonstrated that PAC was effective at enhancing $\operatorname{As}(\mathrm{V})$ removal [45], and high content of basic groups of PAC might favor adsorption of As [46]. In the present study, commercial PAC was used to adsorb DMA, followed by coagulation. Fig. 7 shows that the removal of DMA increased by about $14 \%$ after the addition of $5 \mathrm{mg} / \mathrm{LPAC}$, but remained relatively unchanged with the further increase in PAC dosage. Results showed that PAC adsorption was not an efficient option for enhancing DMA removal. Chitosan or modified chitosan derivatives were also used as coagulant aids to remove As, since the amine groups of chitosan can interact with anions [47]. Results showed that chitosan hardly improved the removal of DMA.

\section{Conclusions}

We showed that FC was much more efficient than $\mathrm{AC}$ and $\mathrm{PACl}$ in relation to methylated As removal by coagulation. Compared with DMA, As $(\mathrm{V})$ and MMA were more easily removed. The coagulation removal efficiency of methylated As was negatively correlated with the degree of methyl substitution. Adsorption onto Fe/Al hydroxide flocs was the predominant mechanism for MMA and DMA removal, and precipitation or co-precipitation might also play a specific role at low coagulant doses. Adsorption affinity decreased with the increase in the degree of methyl substitution.

The smallest quantity of negatively charged species of DMA in water and its larger molecular size were mainly responsible for the lower removal efficiency of DMA by coagulation. The As-O group of As substituted the $\mathrm{O}-\mathrm{H}$ group of $\mathrm{Fe} / \mathrm{Al}$ hydroxide to form a complex, which might be the interaction mechanism between methylated As and Fe/Al flocs. The unstable structure of the complex formation between DMA and Fe/Al hydroxide might also lead to the poor removal of DMA by coagulation. The DMA methyl group was difficult to destroy by conventional oxidants. PAC and chitosan were also not effective coagulant aids to improve the removal of DMA.

\section{Acknowledgements}

The authors are grateful for financial support from the National Natural Science Foundation of China (Nos. 51378490 and 51225805) and the key project of the National " 863 " High-tech R\&D Program of China (2012AA062604).

\section{Appendix A. Supplementary data}

Supplementary data associated with this article can be found, in the online version, at http://dx.doi.org/10.1016/j.jhazmat. 2015.03.055.

\section{References}

[1] K.P. Raven, A. Jain, R.H. Loeppert, Arsenite and arsenate adsorption on ferrihydrite: kinetics, equilibrium, and adsorption envelopes, Environ. Sci. Technol. 32 (1998) 344-349.

[2] A.K. Sharma, J.C. Tjell, J.J Sloth, P.E. Holm, Review of arsenic contamination, exposure through water and food and low cost mitigation options for rural areas, Appl. Geochem. 41 (2014) 11-33.

[3] Y.M. Zheng, L. Yu, J.P. Chen, Removal of methylated arsenic using a nanostructured zirconia-based sorbent: process performance and adsorption chemistry, J. Colloid Interface Sci. 367 (2012) 362-369.

[4] L.C.D. Anderson, K.W. Bruland, Biogeochemistry of arsenic in natural waters the importance of methylated species, Environ. Sci. Technol. 25 (1991) 420-427.

[5] D. Sanchez-Rodas, J.L. Gomez-Ariza, I. Giraldez, A. Velasco, E. Morales, Arsenic speciation in river and estuarine waters from southwest Spain, Sci. Total Environ. 345 (2005) 207-217.

[6] N.F. Lin, J. Tian, J.M. Bian, The study on environmental geo-chemical characteristics in arseniasis area in the Inner Mongolia, World Geol. 18 (1999) 83-88.

[7] E. Dopp, L.M. Hartmann, A.M. Florea, A.W. Rettenmeier, A.V. Hirner, Environmental distribution analysis, and toxicity of organometal(loid) compounds, Crit. Rev. Toxicol. 34 (2004) 301-333.

[8] M.M. Ghosh, J.R. Yuan, Adsorption of inorganic arsenic and organoarsenicals on hydrous oxides, Environ. Prog. 6 (1987) 150-157.

[9] C.D. Cox, M.M. Ghosh, Surface complexation of methylated arsenates by hydrous oxides, Water Res. 28 (1994) 1181-1188.

[10] N.E. Korte, Q. Fernando, A review of arsenic(III) in groundwater, Crit. Rev. Environ. Control 21 (1991) 1-39.

[11] T. Watanabe, S. Hirano, Metabolism of arsenic and its toxicological relevance, Arch. Toxicol. 87 (2013) 969-979.

[12] Z.Q. Cheng, A. Van Geen, R. Louis, N. Nikolaidis, R. Bailey, Removal of methylated arsenic in groundwater with iron filings, Environ. Sci. Technol. 39 (2005) 7662-7666

[13] B.J. Lafferty, R.H. Loeppert, Methyl arsenic adsorption and desorption behavior on iron oxides, Environ. Sci. Technol. 39 (2005) 2120-2127.

[14] D. Pokhrel, T. Viraraghavan, Organic arsenic removal from an aqueous solution by iron oxide-coated fungal biomass: an analysis of factors influencing adsorption, Chem. Eng. J. 140 (2008) 165-172.

[15] M. Shimizu, M. Ginder-Vogel, S.J. Parikh, D.L. Sparks, Molecular scale assessment of methylarsenic sorption on aluminum oxide, Environ. Sci. Technol. 44 (2010) 612-617.

[16] M. Tanaka, Y. Takahashi, N. Yamaguchi, A study on adsorption mechanism of organoarsenic compounds on ferrihydrite by XAFS, 15th International Conference on X-Ray Absorption Fine Structure (Xafs15) 430 (2013).

[17] C.Y. Jing, X.G. Meng, S.Q. Liu, S. Baidas, R. Patraju, C. Christodoulatos, G.P. Korfiatis, Surface complexation of organic arsenic on nanocrystalline titanium oxide, J. Colloid Interface Sci. 290 (2005) 14-21.

[18] J.G. Hering, P.Y. Chen, J.A. Wilkie, M. Elimelech, S. Liang, Arsenic removal by ferric chloride, J. Am. Water Works Assn. 88 (1996) 155-167. 
[19] S. Bordoloi, S.K. Nath, S. Gogoi, R.K. Dutta, Arsenic and iron removal from groundwater by oxidation-coagulation at optimized $\mathrm{pH}$ : laboratory and field studies, J. Hazard. Mater. 260 (2013) 618-626.

[20] R.C. Cheng, H.C. Wang, M.D. Beuhler, Enhanced coagulation for arsenic removal, J. Am. Water Works Assn. 86 (1994) 79-90.

[21] J.G. Hering, P.Y. Chen, J.A. Wilkie, M. Elimelech, Arsenic removal from drinking water during coagulation, J. Environ. Eng. Sci. 123 (1997) 800-807.

[22] X.G. Meng, S. Bang, G.P. Korfiatis, Effects of silicate, sulfate, and carbonate on arsenic removal by ferric chloride, Water Res. 34 (2000) 1255-1261.

[23] G.S. Zhang, Z.M. Ren, X.W. Zhang, J. Chen, Nanostructured iron(III)-copper(II) binary oxide: a novel adsorbent for enhanced arsenic removal from aqueous solutions, Water Res. 47 (2013) 4022-4031.

[24] R.Z. Zhao, J.T. Novak, C.D. Goldsmith, Treatment of organic matter and methylated arsenic in landfill biogas condensate, Waste Manage. 33 (2013) 1207-1214.

[25] J.W. Akitt, A. Farthing, Al-27 nuclear magnetic-resonance studies of the hydrolysis of aluminum(III).5. Slow hydrolysis using aluminum metal, J. Chem. Soc. Dalton Trans. (7) (1981) 1624-1628.

[26] D.R. Parker, P.M. Bertsch, Identification and quantification of the $\mathrm{Al}_{13}$ tridecameric polycation using ferron, Environ. Sci. Technol. 26 (1992) 908-914.

[27] J.M. Duan, J. Gregory, Coagulation by hydrolysing metal salts, Adv. Colloid Interface Sci. 100 (2003) 475-502.

[28] M. Kang, T. Kamei, Y. Magara, Comparing polyaluminum chloride and ferric chloride for antimony removal, Water Res. 37 (2003) 4171-4179.

[29] C.Z. Hu, H.J. Liu, G.X. Chen, J.H. Qu, Effect of aluminum speciation on arsenic removal during coagulation process, Sep. Purif. Technol. 86 (2012) 35-40.

[30] X.J. Guo, Z.J. Wu, M.C. He, Removal of antimony(V) and antimony(III) from drinking water by coagulation-flocculation-sedimentation (CFS), Water Res. 43 (2009) 4327-4335.

[31] C.Z. Hu, G.X. Chen, H.J. Liu, H. Zhao, J.H. Qu, Characterization of flocs generated by preformed and in situ formed Al-13 polymer, Chem. Eng. J. 197 (2012) 10-15.

[32] V. Pallier, G. Feuillade-Cathalifaud, B. Serpaud, J.C. Bollinger, Effect of organic matter on arsenic removal during coagulation/flocculation treatment, J. Colloid Interface Sci. 342 (2010) 26-32.

[33] G.S. Zhang, J.H. Qu, H.J. Liu, R.P. Liu, G.T. Li, Removal mechanism of As(III) by a novel Fe-Mn binary oxide adsorbent: oxidation and sorption, Environ. Sci. Technol. 41 (2007) 4613-4619.

[34] B.A. Manning, S.E. Fendorf, S. Goldberg, Surface structures and stability of arsenic(III) on goethite: spectroscopic evidence for inner-sphere complexes, Environ. Sci. Technol. 32 (1998) 2383-2388.
[35] S. Goldberg, C.T. Johnston, Mechanisms of arsenic adsorption on amorphous oxides evaluated using macroscopic measurements vibrational spectroscopy, and surface complexation modeling, J. Colloid Interface Sci. 234 (2001) 204-216.

[36] S.R. Kanel, B. Manning, L. Charlet, H. Choi, Removal of arsenic(III) from groundwater by nanoscale zero-valent iron, Environ. Sci. Technol. 39 (2005) 1291-1298.

[37] S.F. Lim, Y.M. Zheng, J.P. Chen, Organic arsenic adsorption onto a magnetic sorbent, Langmuir 25 (2009) 4973-4978.

[38] S. Music, D. Dragcevic, S. Popovic, Hydrothermal crystallization of boehmite from freshly precipitated aluminium hydroxide, Mater. Lett. 40 (1999) 269-274.

[39] C.Y. Han, H.P. Pu, H.Y. Li, L. Deng, S. Huang, S.F. He, Y.M. Luo, The optimization of $\mathrm{As}(\mathrm{V})$ removal over mesoporous alumina by using response surface methodology and adsorption mechanism, J. Hazard. Mater. 254 (2013) 301-309.

[40] P. Pillewan, S. Mukherjee, T. Roychowdhury, S. Das, A. Bansiwal, S. Rayalu, Removal of $\mathrm{As}(\mathrm{III})$ and $\mathrm{As}(\mathrm{V})$ from water by copper oxide incorporated mesoporous alumina, J. Hazard. Mater. 186 (2011) 367-375.

[41] Y. Arai, E.J. Elzinga, D.L. Sparks, X-ray absorption spectroscopic investigation of arsenite and arsenate adsorption at the aluminum oxide-water interface, J. Colloid Interface Sci. 235 (2001) 80-88.

[42] M. Shimizu, Y. Arai, D.L. Sparks, Multiscale assessment of methylarsenic reactivity in soil. 1. Sorption and desorption on soils, Environ. Sci. Technol. 45 (2011) 4293-4299.

[43] A.C.Q. Ladeira, V.S.T. Ciminelli, H.A. Duarte, M.C.M. Alves, A.Y. Ramos, Mechanism of anion retention from EXAFS and density functional calculations: arsenic (V) adsorbed on gibbsite, Geochim. Cosmochim. Acta 65 (2001) 1211-1217.

[44] P.D. Kuhlmeier, S.P. Sherwood, Treatability of inorganic arsenic and organoarsenicals in groundwater, Water Environ. Res. 68 (1996) 946-951.

[45] D. Mohan, C.U. Pittman Jr., Arsenic removal from water/wastewater using adsorbents - a critical review, J. Hazard. Mater. 142 (2007) 1-53.

[46] T. Budinova, D. Savova, B. Tsyntsarski, C.O. Ania, B. Cabal, J.B. Parra, N. Petrov, Biomass waste-derived activated carbon for the removal of arsenic and manganese ions from aqueous solutions, Appl. Surf. Sci. 255 (2009) 4650-4657.

[47] L. Pontoni, M. Fabbricino, Use of chitosan and chitosan-derivatives to remove arsenic from aqueous solutions - a mini review, Carbohydr. Res. 356 (2012) 86-92. 